\title{
PROTOTYPE PENGENDALIAN MOTOR UNTUK MENSTABILKAN pH AIR KOLAM IKAN LELE MENGGUNAKAN SENSOR PH DAN ULTRASONIC BERBASIS ARDUINO UNO
}

${ }^{1}$ Rian Ari Wibowo, ${ }^{2}$ Mochammad Djaohar, ${ }^{3}$ Nur Hanifah Y

1,2,3 PendidikanTeknik Elektro, Fakultas Teknik, Universitas Negeri Jakarta

${ }^{1}$ Email : rianariwibowo@gmail.com

\begin{abstract}
.
The research aimed to design and make motor control device to keep $\mathrm{pH}$ of catfish pond water using Arduino Uno pH and ultrasonic sensor. Research using Research and Development (Research and Development) which includes design, system requirement analysis, design, testing and system implementation. Research consists of three main subsystems, namely input, system and output. Sub-system consists of pH sensor, Ultrasonic and Flowmeter to manage the automation process in maintaining water quality in catfish pond contained in Arduino Uno microcontroller. The output subsystems are AC and DC motors for dewatering, filling and checking samples to be displayed on the LCD.

Based on the results of the over all testing that has been done, it is known that the motor control device to maintain the $\mathrm{pH}$ of the water catfish pond using $\mathrm{pH}$ and ultrasonic sensor based Arduino Uno able to maintain the condition of catfish pond water in the conditions suitable for catfish habitat, that is with pH $6.5-8$.
\end{abstract}

Keywords: Catfish (Clariasspp), pH Stabilizer, Arduino Uno, pH Sensor, Ultrasonic.

\section{Abstrak}

Penelitian bertujuan untuk merancang dan membuat Alat pengendalian motor untuk menjaga $\mathrm{pH}$ air kolam ikan lele menggunakan sensor $\mathrm{pH}$ dan ultrasonic berbasis Arduino Uno.

Penelitian menggunakan Metode Penelitian dan Pengembangan (Research and Development) yang meliputi perancangan, analisis kebutuhan sistem, perancangan, pengujian dan implementasi sistem. Penelitian terdiri dari 3 subsistem utama, yaitu input, sistem dan output.subsistem input terdiri dari sensor $\mathrm{pH}$, Ultrasonic dan Flowmeter untuk mengatur proses otomatisasi dalam menjaga kualitas air pada kolam lele yang terdapat didalam mikrokontroler Arduino Uno. Subsistem outputnya adalah motor AC dan DC untuk melakukan pengurasan, pengisian dan pengecekan sampel yang akan di tampilkan pada LCD.

Berdasarkan hasil pengujian secara keseluruhan yang telah dilakukan, diketahui bahwa alat pengendalian motor untuk menjaga $\mathrm{pH}$ air kolam ikan lele menggunakan sensor $\mathrm{pH}$ dan ultrasonic berbasis Arduino Uno mampu menjaga kondisi air kolam lele dalam kondisi sesuai bagi habitat lele, yaitu dengan pH 6,5 - 8 .

Kata Kunci : Ikan Lele (Clariasspp), Penstabil pH, Arduino Uno, Sensor pH, Sensor Ultrasonic

\section{PENDAHULUAN}

Pada kolam tepat pembudidayaan ikan lele penting diperhatikan kondisi air kolam. Air dengan kondisi tidak memenuhi syarat merupakan sumber penyakit yang akan berbahaya bagi pertumbuhan ikan lele. Menurut M. Ghufran (2010), Kualitas air yang dianggap baik untuk kehidupan lele sangkuriang antara lain suhu air optimum dalam pemeliharaan ikan lele sangkuriang secara intensif adalah $25-30{ }^{0} \mathrm{C}$. Adapun parameter lain yang harus diperhatikan adalah umumnya ikan lele hidup normal di lingkungan yang memiliki kandungan oksigen terlarut $4 \mathrm{Mgl}$. Keasaman atau $\mathrm{pH}$ yang baik bagi lele sangkuriang adalah 6,5-9. $\mathrm{pH}$ kurang dari 5 sangat buruk bagi lele sangkuriang karena dapat menyebabkan penggumpalan lender pada insang, sedangkan $\mathrm{pH}$ diatas 9 akan menyebabkan berkurangnya nafsu makan lele sangkuriang.

Pada penelitian sebelumnya yang dilakukan Al Qalit (2017) yaitu jurnal Rancang Bangun
Prototype Pemantauan Kadar $\mathrm{pH}$ dan Kontrol Suhu serta Pemberian Pakan Otomatis pada Budidaya Ikan lele Sangkuriang berbasis IoT, menjelaskan bahwa faktor yang perlu diperhatikan dalam pembudidayaan ikan lele antara lain suhu air, kadar $\mathrm{pH}$ dan pemberian pakan harus sesuai dengan pertumbuhan ikan lele. Selain itu, pada jurnal Rancang Bangun Sistem Pengukuran $\mathrm{pH}$ Meter dengan menggunakan mikrokontroler Arduino Uno, menjelaskan bahwa salah satu cara untuk mengetahui air tersebut baik atau tidaknya adalah dengan mengatur kadar keasamannya menggunakan mikrokontroler Arduino Uno yang dapat dibaca melalui layer LCD.

Berdasarkan kasus pembudidayaan ikan lele dapat dianalisis beberapa faktor yang mempengaruhi kualitas air, diantaranya suhu air yaitu $<22{ }^{\circ} \mathrm{C}$ atau $>32{ }^{\circ} \mathrm{C}$, oksigen yang terlarut pada kolam $<4 \mathrm{Mg} / \mathrm{L}$, kandungan amonia yang cukup tinggi, dan tingkat keasaman air yang sering sekali berubah akibat perubahan cuaca seperti 
hujan yang mengandung asam dan sisa pakan lele yang mengendap sehingga membuat air kolam keruh dan memiliki kadar keasaman yang tinggi. (Witjaksono, 2009)

Melihat kondisi tersebut penulis termotivasi membuat sebuah alat yang dapat memantau dan menstabilkan kadar keasaman air sesuai yang diharapkan. Dengan adanya alat penstabil kadar keasaman air otomatis diharapkan dapat membantu mengontrol dan menjaga kondisi air tetap ideal pada pembudidayaan ikan lele, sehingga dapat mengurangi tingkat kematian ikan lele dan meningkatkan produksi ikan lele.

\section{METODE}

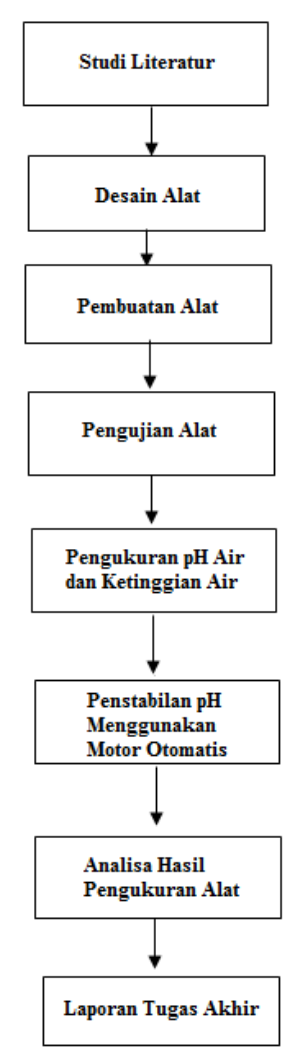

Gambar 1 Diagram Penelitian

Pada tahap awal penelitian yaitu melakukan studi tentang mikrokontroler Arduino Uno, sensor $\mathrm{pH}$, sensor ketinggian (Ultrasonik), flowmeter dan pompa akuarium yang digunakan sebagai alat penstabil $\mathrm{pH}$ atau tingkat keasaman air pada kolam lele.

Tahapan berikutnya adalah menganalisis kebutuhan dan bahan yang akan digunakan dalam prototype penstabil $\mathrm{pH}$ air kolam lele. Kebutuhan alat dan bahan tersebut meliputi alat ukur listrik (multimeter), sensor $\mathrm{pH}$, sensor ketinggian (ultrasonik), flowmeter dan pompa yang digunakan sebagai alat sirkulasi dalam menstabilkan $\mathrm{pH}$ air kolam lele.

Selanjutnya adalah mendesain atau merancang sistem unit penstabil $\mathrm{pH}$ air kolam lele dengan menggunakan sensor $\mathrm{pH}$ dan mikrokontroler Arduino Uno serta membuat propertinya. Setelah itu masuk ke proses tahap pembuatan alat. Pada tahap pembuatan alat akan mengimplementasikan semua bahan dan alat yang dibutuhkan menjadi sebuah prototype alat penstabil $\mathrm{pH}$ air kolam lele. Setelah proses pembuatan alat selesai, maka alat ini harus dilakukan pengujian. Pengujian bertujuan untuk mengetahui dan mengamati kinerja dari alat penstabil pH kolam ikan lele yang telah dibuat serta memperoleh data. Data yang diperoleh pada tahap ini dapat digunakan sebagai acuan pada proses selanjutnya.

Tahapan selanjutnya yaitu menganalisis hasil uji coba alat untuk mengetahui sistem telah berfungsi dengan baik.

Tahapan terakhir adal ah penyusunan laporan pencapaian dari penelitian yang telah dilakukan dengan mengacu pada tujuan dan perumusan masalah yang ditetapkan pada awal penelitian. Hal tersebut kemudian dituangkan dalam bentuk laporan tertulis.

\section{HASIL DAN PEMBAHASAN Pengujian Ketahanan Ikan Lele}

Pengujian pada ketahanan ikan lele bertujuan untuk membuktikan bahwa tingkat keasaman air sangat berpengaruh pada habitat dari ikan lele. Percobaan pertama dilakukan untuk mengetahui tingkat ketahanan ikan lele pada kolam yang memiliki kondisi asam.

Tabel 1 Hasil Uji Coba Ketahanan Lele $\mathrm{pH}<6,5$

\begin{tabular}{ccc}
\hline pH Air & Waktu & Kondisi \\
\hline \multirow{3}{*}{4,8} & 15 menit & Lemas \\
& 30 menit & Lemas \\
& 60 menit & Mati \\
& 15 menit & Lincah \\
5,4 & 30 menit & Lemas \\
& 60 menit & Lemas \\
& 15 menit & Lincah \\
5,8 & 30 menit & Lemas \\
& 60 menit & Lemas \\
& 15 menit & Lincah \\
6,0 & 30 menit & Lincah \\
& 60 menit & Lemas \\
& 15 menit & Lindah \\
6,4 & 30 menit & Lincah \\
& 60 menit & Lincah \\
\hline
\end{tabular}

Percobaan kedua dilakukan untuk mengetahui tingkat ketahanan ikan lele pada kolam yang memiliki kondisi basa. 
Tabel 2 Hasil Uji Coba Ketahanan Lele pH > 8

\begin{tabular}{ccc}
\hline pH Air & Waktu & Kondisi \\
\hline & 15 menit & Lincah \\
8,2 & 30 menit & Lincah \\
& 60 menit & Lincah \\
& 15 menit & Lincah \\
8,6 & 30 menit & Lincah \\
& 60 menit & Lincah \\
& 15 menit & Lincah \\
9,3 & 30 menit & Lemas \\
& 60 menit & Lemas \\
& 15 menit & Lincah \\
9,6 & 30 menit & Lemas \\
& 60 menit & Lemas \\
& 15 menit & Lemas \\
9,9 & 30 menit & Lemas \\
& 60 menit & Lemas \\
\hline
\end{tabular}

\section{Hasil Konversi Sensor pH Terhadap Tegangan}

Pengujian kalibrasi sensor $\mathrm{pH}$ terhadap tegangan dilakukan dengan cara mempersiapkan alat yang dibutuhkan seperti sensor $\mathrm{pH}$ dan multimeter digital. Hal tersebut bertujuan untuk mengkonversi data yang terbaca oleh sensor $\mathrm{pH}$ menjadi tegangan.

Tabel 3 Hasil Konversi Sensor $\mathrm{pH}$ terhadap Tegangan

\begin{tabular}{cc}
\hline $\begin{array}{c}\text { Nilai pH } \\
\text { Sensor }\end{array}$ & Tegangan \\
\hline 1,90 & 4,11 \\
2,88 & 3,93 \\
3,39 & 3,84 \\
4,04 & 3,71 \\
5,70 & 3,40 \\
6,33 & 3,28 \\
7,49 & 3,09 \\
7,96 & 3,22 \\
9,37 & 2,76 \\
10,50 & 2,58 \\
11,82 & 2,36 \\
11,94 & 2,34 \\
13,75 & 2,05 \\
\hline
\end{tabular}

Grafik Nilai pH Terhadap Tegangan

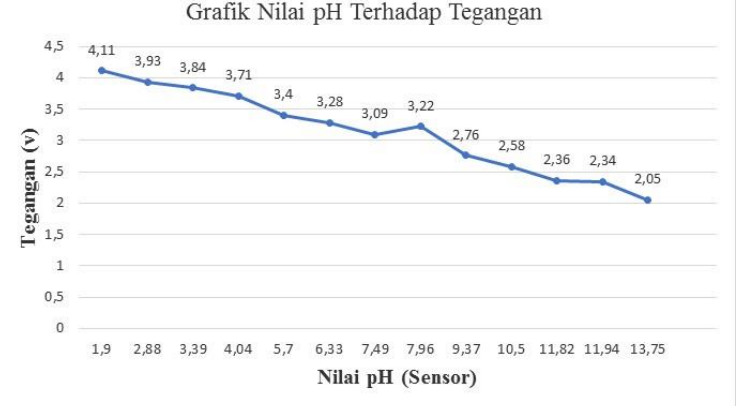

Gambar 1 Grafik Korelasi Nilai pH Terhadap Tegangan

Dari data tersebut dapat di tarik kesimpulan bahwa nilai $\mathrm{pH}$ berbanding terbalik dengan tegangan yang dihasilkan. Semakin tinggi nilai $\mathrm{pH}$ maka tegangan yang dihasilkan semakin rendah. Dan sebaliknya, semakin rendah nilai $\mathrm{pH}$ nya maka tegangan yang dihasilkan semakin tinggi.

Hasil Uji Coba Sensor pH dan pH Meter Alat yang digunakan dalam penelitian untuk mengukur tingkat keasaman $(\mathrm{pH})$ air kolam lele adalah sensor
pH. Oleh karena itu perlu dilakukan uji coba untuk membandingkan hasil pengukuran yang dilakukan dengan sensor $\mathrm{pH}$ dan hasil pengukuran yang dilakukan dengan $\mathrm{pH}$ meter.

Tabel 4 Hasil PerbandinganpH Meter dengan Sensor pH

\begin{tabular}{cccc}
\hline No & $\begin{array}{c}\text { Nilai } \mathbf{p H} \text { air } \\
\mathbf{X}_{\mathbf{1}} \\
\text { (pH meter) }\end{array}$ & $\begin{array}{c}\text { Nilai } \mathbf{p H} \text { air } \\
\mathbf{X}_{\mathbf{2}} \\
\text { (Sensor } \mathbf{p H})\end{array}$ & $\mathbf{\Delta \Sigma}=\mathbf{I} \mathbf{x}_{\mathbf{1}}-\mathbf{X}_{\mathbf{2}} \mathbf{I}$ \\
\hline $\mathbf{1}$ & 6,4 & 5,68 & 0,72 \\
$\mathbf{2}$ & 6,7 & 5,88 & 0,82 \\
$\mathbf{3}$ & 6,8 & 5,90 & 0,9 \\
$\mathbf{4}$ & 7,0 & 7,50 & 0,5 \\
$\mathbf{5}$ & 7,2 & 7,40 & 0,2 \\
$\mathbf{6}$ & 7,3 & 7,37 & 0,07 \\
$\mathbf{7}$ & 8,0 & 7,96 & 0,04 \\
$\mathbf{8}$ & 8,9 & 8,75 & 0,15 \\
$\mathbf{9}$ & 9,3 & 8,45 & 0,85 \\
$\mathbf{1 0}$ & 10,3 & 9,57 & 0,73 \\
\hline
\end{tabular}

\section{Hasil Uji Coba Sensor Ultrasonic}

Alat yang digunakan dalam mengukur ketinggian air kolam lele adalah sensor Ultrasonic. Oleh karena itu perlu dilakukan uji coba untuk mengukur tingkat akurasi alat tersebut dengan membandingkan hasil pengukuran yang dilakukan dengan sensor Ultrasonic dan hasil pengukuran yang dilakukan menggunakan mistar garis.

Tabel 5 Hasil Uji Coba Sensor Ultrasonic

\begin{tabular}{cccc}
\hline No & $\begin{array}{c}\text { Ketinggian Air (cm) } \\
\text { Sen sor }\end{array}$ & $\begin{array}{c}\text { Ketinggian Air (cm) } \\
\text { Mistar }\end{array}$ & $\begin{array}{c}\text { Error } \\
\mathbf{\%}\end{array}$ \\
\hline $\mathbf{1}$ & $10 \mathrm{~cm}$ & $10 \mathrm{~cm}$ & 0 \\
$\mathbf{2}$ & $11 \mathrm{~cm}$ & $11 \mathrm{~cm}$ & 0 \\
$\mathbf{3}$ & $13 \mathrm{~cm}$ & $13 \mathrm{~cm}$ & 0 \\
$\mathbf{4}$ & $15 \mathrm{~cm}$ & $15 \mathrm{~cm}$ & 0 \\
$\mathbf{5}$ & $16 \mathrm{~cm}$ & $16 \mathrm{~cm}$ & 0 \\
$\mathbf{6}$ & $18 \mathrm{~cm}$ & $18 \mathrm{~cm}$ & 0 \\
$\mathbf{7}$ & $19 \mathrm{~cm}$ & $19 \mathrm{~cm}$ & 0 \\
$\mathbf{8}$ & $21 \mathrm{~cm}$ & $21 \mathrm{~cm}$ & 0 \\
$\mathbf{9}$ & $23 \mathrm{~cm}$ & $22 \mathrm{~cm}$ & 4,55 \\
$\mathbf{1 0}$ & $24 \mathrm{~cm}$ & $23 \mathrm{~cm}$ & 4,35 \\
\hline \multicolumn{4}{r}{ Rata - Rata } \\
\hline
\end{tabular}

\section{Hasil Uji Coba Sistem}

Pengujian yang terakhir adalah uji coba alat penstabil $\mathrm{pH}$ otomatis kolam lele secara keseluruhan dengan $\mathrm{pH}$ awal kolam dan ketinggian air kolam berbeda-beda.

\section{Tabel 6 Hasil Uji Coba Sistem}

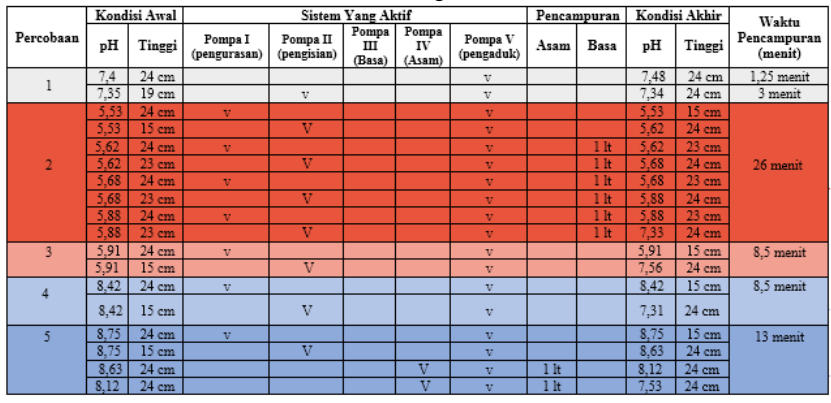

Ketarangan Tabel.

Kondisis sistem dalam kolam lele dengan pH normal

Kondisis istem dalam kolam lele dengan pH asam kuat

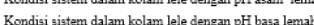




\section{KESIMPULAN DAN SARAN \\ Kesimpulan}

Berdasarkan hasil penelitian yang dilakukan maka dapat disimpulkan bahwa prototype penstabil $\mathrm{pH}$ air kolam ikan lele sudah dapat berjalan sesuai fungsinya. Alat ini mampu mengontrol kondisi air pada kolam lele agar tetap stabil, sehingga dapat mengurangi tingkat kematian ikan akibat kondisi air yang buruk. Selain itu, alat penstabil $\mathrm{pH}$ air kolam ikan lele dapat membantu kinerja pembudidaya, sehingga tidak perlu melakukan pengurasan kolam ikan lele secara konvensional dan dapat meminimalisir waktu dan tenaga

\section{Saran}

1. Penelitian ini harus menggunakan sensor $\mathrm{pH}$ yang lebih akurat.

2. Penelitian ini harus menggunakan sensor ketinggian yang anti air, sehingga lebih tahan lama apabila terkena air.

\section{DAFTAR PUSTAKA}

Al Qalit., Ferdian., Rahman, Aulia. 2017. Rancang Bangun Prototipe Pemantauan Kadar pH dan Kontrol Suhu Serta Pemberian Pakan Otomatis pada Budidaya Ikan lele Sangkuriang Berbasis IoT. Jurnal Teknik Elektro, Vol 2 No. 3: halaman 8-15.

Arief, Ulfah Medianty. 2011. Pengujian Sensor Ultrasonik PING untuk Pengukuran Level Ketinggian dan Volume Air", Tugas Akhir. Semarang: Teknik Elektro, Universitas Negeri Semarang.

Budi Santoso \& Agung Dwi Arfianto. 2014. "Sistem Pengganti Air Berdasarkan Kekeruhan dan Pemberi Pakan Ikan Pada Akuarium Air Tawar Secara Otomatis Berbasis Mikrokontroler ATMEGA 16”, Jurnal. Malang ; Sekolah Tinggi Manajemen Informatika dan Komputer.

Eko Ihsanto \& Sardi Hidayat. 2014. "Rancang Bangun Sistem Penngukuran pH Meter Dengan Mengguunakan Mikrokontroler Arduino Uno", Tugas Akhir. Jakarta ; Teknik Elektro, Universitas Mercu Buana.

Ghufran, M. H., Kordi, K 2010. "Budidaya Ikan Lele di Kolam Terpa;." Penerbit ANDI. Yogyakarta.

Ian Sommerville. (2003), Software Engineering (Rekayasa Perangkat Lunak)/Ian
Sommerville; alih bahasa, Dra.Yuhilza Hanum M.Eng, ; Hilarius Wibi Hardani. Ed.6, Erlangga, Jakarta.

Mulyanto.1992. Lingkungan Hidup Untuk Ikan. Depdikbud, Jakarta.138 Halaman

Prawistasari, Adinda. 2009. Sistem Pemberian Makan dan Monitoring Kadar $\mathrm{pH}$ Air Akuarium Berbasis Mikrokontroler, Tugas Akhir. Jakarta : FMIPA, Universitas Indonesia. Saanin. 1984. Taksonomi dan Kunci Identifikasi Ikan Volume I dan II. Jakarta : Bina Rupa Aksara.

Saidul, Rozeff Pramana. 2013. "Pengontrolan $p H$ Air Secara Otomatis Pada Kolam Pembenihan Ikan Kerapu Macan Berbasis Arduino", Jurnal. Riau : Teknik Elektro, Universitas Maritim Raja Ali Haji.

Sunardi, Refi Aprendi \& Ardoldus Darus. 2016. Pengertian Arduino Uno dan BagianBagiannya. http://www.academia.edu, diakses pada tanggal 20 Mei 2017 pukul (14 : 30).

T. Muchlis Muzakir, et all. 2014. Instrumen Sensor Pada Alat Pengukur pH. http://teukumuchlismuzakir.blogspot.com, diakses pada tanggal 22 Mei 2017 pukul (19: 00).

Wardhana Lingga. 2006, Mikrokontroler AVR Seri ATMEGA 8535. Yogyakarta : Andi

Widodo Budhiarto \& Sigit Firmansyah. 2009, Digital dan Mikroprosesor. Yogyakarta : Andi Witjaksono. 2009. Kinerja Produksi Pendederan Lele Sangkuriang Melalui Penerapan Teknologi Ketinggian Air. 